\title{
Characterization of Abdominal Organs Among Patients with Ascites, Elribat Teaching Hospital, Sudan; Sonographic Study
}

\author{
Taha Ahmed Elmukashfi Elsheikh, ${ }^{1,}$, Elsafi Ahmed Abdullah Balla ${ }^{2}$, \\ Ashraf Mustafa Mohammed Osman ${ }^{3}$ \\ ${ }^{1}$ Department of Community Medicine, University of Khartoum, Khartoum, Sudan \\ ${ }^{2}$ Department of Diagnostic Medical Ultrasound, Sudan University of Science and Technology, Khartoum, Sudan \\ ${ }^{3}$ Alzaitona Specialized Hospital, Khartoum, Sudan
}

Email address:

tahamukashfi@hotmail.com (T. A. E. Elsheikh), alsafi1000@hotmail.com (E. A. A. Balla), ashrafmerafabi@gmail.com (A. M. M. Osman)

${ }^{*}$ Corresponding author

\section{To cite this article:}

Taha Ahmed Elmukashfi Elsheikh, Elsafi Ahmed Abdullah Balla, Ashraf Mustafa Mohammed Osman. Characterization of Abdominal Organs Among Patients with Ascites, Elribat Teaching Hospital, Sudan; Sonographic Study. Central African Journal of Public Health . Vol. 6, No. 6, 2020, pp. 332-338. doi: 10.11648/j.cajph.20200606.13

Received: July 23, 2020; Accepted: October 7, 2020; Published: November 9, 2020

\begin{abstract}
Background: Ascites is an accumulation of excessive fluid in peritoneal cavity. Aim: To determine sonographic appearances of abdominal organs among patients having ascites, attending at Ultrasound Department, Elribat Teaching Hospital, Sudan; 2016. Methods: The study design was a cross sectional study. Independent variable was ascites. Dependent variables were liver echogenisity, size, volume and width; pancreas echogenisity, size, volume and width; spleen echogenisity, size, volume and width; para-aortic lymph nodes echogenicity, diameter, volume, and width; ascetic fluid volume; and kidney echogenisity, size, volume and width. Twenty nine patients were selected. Investigation was done using abdominal ultrasound. Personal data (age, and sex) was obtained by direct interview. Data was analyzed using SPSS version 21. Chi square test at $95 \%$ CL was considered statistically significant. Results: About $65.5 \%$ of them were male; $31 \%$ were in age group (66-80) years, followed (24.1\%) by age group (51-65) years, and least one (3.4\%) was age group (21-35) years; mean age was 56.96 years; minimum age was 8 years; and maximum age was 88 years. Percentage of increased liver echogenicity, volume, width, and diameter; was found to be high. Width and diameter of spleen was increased among most of respondents. There was strong statistical association between echogenicity of liver and that of spleen; between echogenicity, diameter, width, and volume of para-aortic lymph nodes; and ascetic fluid volume. Regarding ascetic fluid volume there was equal distribution of moderate and gross ascites among them. There was statistical association between para-aortic lymph nodes volume and ascetic fluid volume. Echogenicity of spleen together with echogenicity of pancreas were statistically associated with echogenicity of para-aortic lymph nodes. Conclusion and recommendations: Involvement of liver was obvious among patients having ascites. Conduction of a research to correlate sonographic findings with diagnosis of disease is recommended.
\end{abstract}

Keywords: Characterization of Abdominal Organs, Ascites, Sonographic Study, Sudan

\section{Introduction}

\subsection{Background information}

Ascites is the build-up of fluid in the space between the lining of the abdomen and abdominal organs [1]. It is an accumulation of excessive fluid in the peritoneal cavity $[2,3]$.
It results from portal hypertension and hypo-albuminaemia. So, any conditions that lead to severe liver damage, as long standing hepatitis $\mathrm{C}$ or $\mathrm{B}$ viral infection and alcohol addiction, can manifested as ascites e.g. severe liver damage, primary or secondary hepatic cancer, portal vein thrombosis, congestive heart failure, pancreatitis, renal disease, and infectious diseases (e.g. TB, VL) [4-7]. According to the phase of 
menstrual cycle, women may normally have $20 \mathrm{ml}$ or more intra-abdominal fluid. Malignancy should be suspected in women presenting with ovarian mass and ascites [8]. Very small amounts of fluid in the peritoneal cavity can be detected using ultrasound. Depending on the sonographic features, the pathology of ascites can be determined [9]. Large amounts of ascitic fluid, a moderately enlarged liver with normal echo-texture, small kidneys with nephrocalcinosis, can be confirmed using abdominal ultrasound [10]. The minimal amount of fluid that can be detected by clinical examination is $1500 \mathrm{ml}$; such amount varies from one person to another depending on the body weight of the patient. So, it can be less in a small and thin individual; while more in an obese one. Smaller volumes of ascites $(\leq 500 \mathrm{ml})$ can be detected by ultrasound. Ascetic fluid can be sterile or infected. Sterile ascites which is not associated with hepato-renal syndrome can be graded as follows [3]:

Grade 1: It is the mild ascites which is detected only by ultrasound.

Grade 2: It is the moderate one that leading to moderate symmetrical distension of the abdomen.

Grade 3: It is the large one which is characterized by marked abdominal distension.

Refractory ascites can be divided into two groups: (i) Diuretic-resistant ascites: It is refractory to dietary sodium restriction and intensive diuretic treatment for at least one week. (ii) Diuretic-intractable ascites: It is refractory to therapy due to the development of diuretic-induced complications that preclude the use of an effective dose of diuretic [3].

Differentiation between transudate and exudate ascites can be obtained with high accuracy using ultrasound. So, it is the best method in the absence CT and MRI, and it complement for laboratory investigations on ascites [11]. Etiology and volume of ascites are directly associated with the SAAG. Ascites Albumin Gradient (SAAG) stands for the Serum Albumin Concentration minus the ascitic fluid albumin concentration. So, ultrasound can be used for detecting the etiological factors of ascites. As little as $10 \mathrm{ml}$ of free fluid can be detected sonographically. Up to $50 \mathrm{ml}$ of fluid normally present in the peritoneal cavity. Accumulation of at least $1500 \mathrm{ml}$ of fluid gives clinical ascites [12].

Fluid in the abdomen can move freely up the right pericolic gutter into Morison's pouch, the potential space in the hepatorenal recess. The flow of fluid in the left pericolic gutter is higher and the phrenicocolic ligament blocks the flow. So, fluid accumulates more in the right side. Regarding pelvic region fluid flows to the retrovesicular area in the male patient and to the pouch of Douglas in the female patient because these areas are the most dependent areas of the pelvis [13].

The gastrointestinal tract tuberculosis is the sixth most frequent type of extra-pulmonary tuberculosis. The others are: lymphatic, genitourinary, bone and joint, miliary and meningeal type. The percentage of abdominal tuberculosis among TB patients is about $5 \%$. The ileocaecal region is the most common site of gastrointestinal tract for involvement with tuberculosis. It presents with a palpable mass in the right lower quadrant with or without obstruction, perforation or malabsorption. Examination of ascetic fluid indicates straw-coloured fluid with high protein and lymphocytic cells [14]. Ascites is the most common manifestation in cirrhotic patients, and is associated with a reduced survival rate [15]. Approximately $75 \%$ of patients presenting with ascites have underlying cirrhosis, and about $50 \%$ of patients with cirrhosis will develop ascites over a 10 -year period of follow-up. Fluid retention (primarily ascites, but also peripheral oedema and pleural effusions) is the most frequent complication of end-stage liver disease. It significantly impairs the quality of life of patients with cirrhosis and is associated with poor prognosis, 1-year and 5 -year survival rates of $85 \%$ and $56 \%$, respectively [16]. In a patient with a very long history of stable cirrhosis who then develops ascites - hepatocellular carcinoma must be excluded. Malignancy accounts for around $15 \%$. The usual causes are: Malignancies of the gastrointestinal tract (carcinoma of stomach, colon, pancreas; primary hepatocellular carcinoma and metastatic liver cancer). Carcinoma of ovary: Meigs' syndrome is a rare complication of ovarian cancer and produces ascites out of all proportion to the size of the tumour and pleural effusions, often unilateral. Hodgkin's lymphoma and nonHodgkin's lymphoma, Metastatic carcinoma within the abdominal cavity, Heart failure, Nephrotic syndrome, Protein-losing enteropathy, Tuberculosis, Pancreatitis, Other rare causes, including hypothyroidism, Iatrogenic, eg ovarian hyperstimulation as a consequence of IVF procedure; any one of these can be manifested by ascites [15]. Bilharzialperiportal fibrosis is well identified by ultrasound. The changes related to bilharzial infection can be well studied and analyzed using this method. So, the resulting classifications are more reliable than that depending on clinical examination alone. Classification depending on physical examination does not consider the present periportal fibrosis and classified cases as intestinal which are actually hepato-intestinal. Thus, the pathological processes will be assessed efficiently using ultrasound. Bearing in mind that hepatic biopsy is the best way for detecting liver changes related to bilharzias, but is an invasive method and can be done only in hospital. Evaluation of fibrosis and portal hypertension in an area of low endemicity of schistosomiasis, in the municipality of Bananal, São Paulo, is done using abdominal ultrasound together with stool examination. Five patients out of 109 have positive stool test. Ultrasonography of these five patients shows either peripheral or central periportal fibrosis or portal hypertension; while the others show no sonographic findings. So, ultrasonography is a noninvasive, sensitive diagnostic method for identification of the extent of liver involvement in schistosomiasis cases [9]. Findings of abdominal ultrasound in early abdominal tuberculosis are an increase in mesenteric echogenicity (due to fat deposition), mesenteric lymphadenopathy, with mesenteric 
thickness of $15 \mathrm{~mm}$ or more, dilated small bowel loops and ascites [17]. Sonographic findings of abdominal tuberculosis with HIV, in a patient having prolongrd fever and low CD4, are lymphadenopathy (size $>15 \mathrm{~mm}$ ) with hypoechoic/necrotic eckotecture, and hepatospleenomegaly with hypoechoic lesions. Ultrasound is widely used, noninvasive, and affordable tool that may be used to diagnose abdominal tuberculosis in a patient being infected with HIV [18]. The commonest sonographic findings in tuberculous seropositive HIV patients are ascites, para-aortic lymphadenopathy (over $1 \mathrm{~cm}$ in size), and hepatomegaly [14] [19]. One of the most common extrapulmonary sites of tuberculous infection is the peritoneum. Here ultrasound of the abdomen played an important role in the diagnostic process [20]. The minimum amount of intraperitoneal fluid that can be detected by abdominal sound is about $100 \mathrm{ml}$ $[16,21]$. Ultrasonography is a sensitive, noninvasive diagnostic method that allows a better identification of the extent of liver involvement in schistosomiasis cases [14].

\subsection{Problem Statement and Justification}

Sudan is one of the countries with high prevalence of both bilharziasis and tuberculosis which lead to development of ascites. This justifies the important of uses of ultrasound to help in the diagnosis of the possible cause/s of such ascites. To my knowledge there are no published data regarding this issue among Sudanese patients. So, during the year 2016 we investigated patients, having ascites, attended at Ultrasound Department in Elribat Teaching Hospital, Sudan; in order to find out the different sonographic appearances of the abdominal organs; and we tried to highlight the important points related to this topic.

\subsection{Aim of the study}

It aim is to determine sonographic appearances of abdominal organs among patients having ascites, attending at Ultrasound Department, Elribat Teaching Hospital, Sudan; 2016.

\section{Materials and Methods}

\subsection{Study Design}

It was a cross sectional facility base study.

\subsection{Study Area}

It was done in Elribat Teaching Hospital. This hospital is located near the Blue Nile, in Khartoum State, Khartoum City, Sudan. It serves the policemen and the students of Elribat University.

\subsection{Study Population}

They were patients having ascites attending Ultrasound Department at Elribat Teaching Hospital during the year 2016.

\subsection{Sampling}

\subsubsection{Sample Frame}

Patients having ascites.

\subsubsection{Sample Size}

Twenty nine patients were selected.

\subsection{Variables}

Independent variable wasascites. Dependent variables wereliverechogenisity, size, volume and width; pancreas echogenisity, size, volume and width; spleen echogenisity, size, volume and width; para-aortic lymph nodes echogenicity, diameter, volume, and width; ascetic fluid volume; and kidney echogenisity, size, volume and width.

\subsection{Data Collection Methods and Techniques}

Investigation was done using abdominal ultrasound. Personal data (age, and sex) was obtained by direct interview.

\subsection{Data Management and Analysis}

Data was analyzed using SPSS version 21. Chi square test at $95 \% \mathrm{CL}$ was considered statistically significant.

\subsection{Ethical Concern}

Ethical approval was obtained from Sudan University of Science and Technology, College of Postgraduate Studies and Scientific Research, and then patients consent was taken from each of them.

\section{Results}

Most of the respondents (31\%) were in the age group (66-80) years, followed $(24.1 \%)$ by the age group $(51-65)$ years, and the least one $(3.4 \%)$ was the age group (21-35) years. The mean age was 56.96 years; median was 65 ; minimum age was 8 years; and maximum age was 88 years. About $65.5 \%$ of the respondents were male, while $34.5 \%$ of them were female.

About $18(62.1 \%)$ of the respondents had an increased liver echogenesity; while only $8(27.6 \%)$ of them had normal liver echogenesity. An increased liver volume was reported among about $16(55.2 \%)$ of the study population; while the normal liver volume was recorded among only 7 (24.1\%) of them. There was an increased liver width among $15(51.7 \%)$ and normal width among only $5(17.2 \%)$ of them. The liver diameter was increased among $15(51.7 \%)$ and normal among $5(17.2 \%)$.

For spleen the echogenesity was found to be increased among 2 (6.9\%) and normal among 24 (82.8\%); the size was found to be increased among $12(41.4 \%)$ and was normal among $14(48.3 \%)$; the width was found to be increased among $14(48.3 \%)$ and was normal among $12(41.4 \%)$; the diameter was found to be increased among $14(48.3 \%)$ and was normal among 12 (41.4\%).

Regarding the pancreas the echogenesity was found to be increased among only $1(3.4 \%)$ and normal among 10 
(34.5\%); the volume of the was increased among $2(6.9 \%)$ and was normal among $9(31.0 \%)$; the width of was found to be increased among $2(6.9 \%)$ and was normal among 9 $(31.0 \%)$; and the diameter was found to be increased among $2(6.9 \%)$ and normal among $9(31.0 \%)$.

About the right kidney of the respondents, we found thattheechogenesity was increased among $20(69.0 \%)$ and normal among 4 (13.8\%); the volume was increased among 6 $(20.7 \%)$ and normal among $19(65.5 \%)$; the width was increased among 4 (13.8\%) and normal among 20 (69.0\%); and the diameter was increased among $4(13.8 \%)$ and normal among 20 (69.0\%).

The sonographic findings of the left kidney indicated that its echogenesity was increased among 18 (62.1\%) and normal among 6 (20.7\%); its volume was increased among 5 $(17.2 \%)$ and normal among $21(72.4 \%)$; its width was increased among 5 (17.2\%) and normal among 21 (72.4\%); and its diameter was increased among $5(17.2 \%)$ and normal among 21 (72.4\%).

Regarding para-aortic lymph nodes its echogenesity was increased among $3(10.3 \%)$ and normal among $4(13.8 \%)$, its volume was increased among $3(10.3 \%)$ and normal among 5 $(17.2 \%)$; its width was increased among $1(3.4 \%)$ and normal among 3 (10.3\%); and its diameter was increased among only $1(3.4 \%)$ and normal among $3(10.3 \%)$.

The sonographic study of the ascetic fluid showed that there was moderate ascites among $13(44.8 \%)$ and gross ascites among $13(44.8 \%)$.

Table 1. Cross tabulation of the echogenesityof the liver and that of the spleen of the respondents with ascites attending Ultrasound Department, Elribat Teaching Hospital, Sudan; 2016 ( $n=29)$.

\begin{tabular}{lllll}
\hline \multirow{2}{*}{ Liver echogenesity } & \multicolumn{2}{l}{ Spleen echogenesity } & \multicolumn{2}{c}{ Normal } \\
\cline { 2 - 5 } & Missed & Increased & 1 & 3 \\
\hline Decreased & 0 & 2 & 16 & 18 \\
Increased & 2 & 0 & 7 & 8 \\
Normal & 1 & 0 & 24 & 29 \\
Total & 3 & 2 & 0.001 & \\
\hline
\end{tabular}

There was strong statistical association between echogenesity of the liver and that of the spleen $(P$ value $=0.001)($ Table 1$)$.

Table 2. Cross tabulation of the echogenesityof the liver and that of the para-aortic lymph nodes of the respondents with ascites attending Ultrasound Department, Elribat Teaching Hospital, Sudan; 2016 (n=29).

\begin{tabular}{|c|c|c|c|c|c|c|}
\hline \multirow{2}{*}{ Liver echogenesity } & \multicolumn{4}{|c|}{ Para-aortic lymph nodes echogenesity } & \multirow{2}{*}{ Total } & \multirow{2}{*}{ Pvalue } \\
\hline & Missed & Increased & Normal & Not seen & & \\
\hline Decreased & 0 & 0 & 3 & 0 & 3 & \\
\hline Increased & 2 & 2 & 0 & 14 & 18 & 0.001 \\
\hline Normal & 1 & 1 & 1 & 5 & 8 & \\
\hline Total & 3 & 3 & 4 & 19 & 29 & \\
\hline
\end{tabular}

There was strong statistical association between echogenesity of the liver and that of the para-aortic lymph nodes $(P$ value $=0.001$ ) (Table 2).

Table 3. Cross tabulation of the liver echogenesity and para-aortic lymph nodes diameter of the respondents with ascites attending Ultrasound Department, Elribat Teaching Hospital, Sudan; 2016 ( $n=29)$.

\begin{tabular}{lllllll}
\hline \multirow{2}{*}{ Liver echogenesity } & \multicolumn{2}{l}{ Para-aortic lymph nodes diameter } & Total & \multirow{2}{*}{$\boldsymbol{P}$ value } \\
\cline { 2 - 6 } & Missed & Increased & Normal & Not seen & & \\
\hline Decreased & 1 & 0 & 2 & 0 & 3 & 0.024 \\
Increased & 3 & 1 & 0 & 14 & 8 & \\
Normal & 2 & 0 & 1 & 18 & 29 & \\
Total & 6 & 1 & 3 & 19 & & \\
\hline
\end{tabular}

There was statistical association between the echogenesity of the liver and the diameter of para-aortic lymph nodes of the respondents $(P$ value $=0.024)$ (Table 3$)$.

Table 4. Cross tabulation of the liver echogenesity and para-aortic lymph nodes width of the respondents with ascites attending Ultrasound Department, Elribat Teaching Hospital, Sudan; $2016(n=29)$.

\begin{tabular}{llllll}
\hline \multirow{2}{*}{ Liver echogenesity } & \multicolumn{2}{l}{ Para-aortic lymph nodes width } & & Not seen & P value \\
\cline { 2 - 5 } & Missed & Increased & Normal & 0 & 3 \\
\hline Decreased & 1 & 0 & 2 & 14 & 18 \\
Increased & 3 & 1 & 0 & 5 & 8 \\
Normal & 2 & 0 & 1 & 19 & 29 \\
Total & 6 & 1 & 3 & 024 & \\
\hline
\end{tabular}

There was statistical association between the echogenesity of the liver and the width of para-aortic lymph nodes of the respondents $(P$ value $=0.024)$ (Table 4$)$. 
Table 5. Cross tabulation of the liver echogenesity and para-aortic lymph nodes volume of the respondents with ascites attending Ultrasound Department, Elribat Teaching Hospital, Sudan; 2016 ( $n=29)$.

\begin{tabular}{|c|c|c|c|c|c|c|}
\hline \multirow{2}{*}{ Liver echogenesity } & \multicolumn{4}{|c|}{ Para-aortic lymph nodes volume } & \multirow{2}{*}{ Total } & \multirow{2}{*}{ Pvalue } \\
\hline & Missed & Increased & Normal & Not seen & & \\
\hline Decreased & 0 & 0 & 3 & 0 & 3 & \multirow{4}{*}{0.010} \\
\hline Increased & 1 & 2 & 1 & 14 & 18 & \\
\hline Normal & 1 & 1 & 1 & 5 & 8 & \\
\hline Total & 2 & 3 & 5 & 19 & 29 & \\
\hline
\end{tabular}

There was statistical association between echogenesity of the liver and volume of para-aortic lymph nodes of the respondents $(P$ value $=0.010)$ (Table 5).

Table 6. Cross tabulation of the echogenesityof the spleen and that of the para-aortic lymph nodes of the respondents with ascites attending Ultrasound Department, Elribat Teaching Hospital, Sudan; 2016 ( $n=29)$.

\begin{tabular}{|c|c|c|c|c|c|c|}
\hline \multirow{2}{*}{ Spleen echogenesity } & \multicolumn{4}{|c|}{ Para-aortic lymph nodes echogenesity } & \multirow{2}{*}{ Total } & \multirow{2}{*}{ Pvalue } \\
\hline & Missed & Increased & Normal & Not seen & & \\
\hline Missed & 1 & 0 & 0 & 2 & 3 & \\
\hline Increased & 0 & 0 & 2 & 0 & 2 & 0.016 \\
\hline Normal & 2 & 3 & 2 & 17 & 24 & \\
\hline Total & 3 & 3 & 4 & 19 & 29 & \\
\hline
\end{tabular}

There was statistical association between echogenesity of the spleen and that of the para-aortic lymph nodes of the respondents $(P$ value $=0.016)$ (Table 6).

Table 7. Cross tabulation of the echogenesityof the pancreas and that of the para-aortic lymph nodes of the respondents with ascites attending Ultrasound Department, Elribat Teaching Hospital, Sudan; 2016 ( $n=29)$.

\begin{tabular}{llllll}
\hline \multirow{2}{*}{ Pancreasechogenesity } & \multicolumn{2}{l}{ Para-aortic lymph nodes echogenesity } & & Not seen \\
\cline { 2 - 5 } Missed & Increased & Normal & 0 & Palue \\
\hline Missed & 1 & 1 & 1 & 0 & 3 \\
Increased & 0 & 1 & 0 & 5 & 1 \\
Normal & 1 & 1 & 3 & 14 & 10 \\
Not seen & 1 & 0 & 0 & 19 & 29 \\
Total & 3 & 3 & 4 & 0.008 \\
\hline
\end{tabular}

There was statistical association between echogenesity of the pancreas and hat of thepara-aortic lymph nodes $(P$ value $=0.008$ ) (Table 7).

Table 8. Cross tabulation of the liver echogenesity and ascetic fluid volume among the respondents with ascites attending Ultrasound Department, Elribat Teaching Hospital, Sudan; 2016 ( $n=29)$.

\begin{tabular}{lllllll}
\hline \multirow{2}{*}{ Liver echogenesity } & \multicolumn{2}{l}{ Ascetic fluid volume } & \multirow{2}{*}{ Total } & \multirow{2}{*}{ P value } \\
\cline { 2 - 5 } & Missed & Minor ascites & Moderate ascites & Gross ascitis & 2 & 3 \\
Decreased & 0 & 0 & 1 & 5 & 18 & 0.024 \\
Increased & 1 & 0 & 12 & 6 & 8 & 29 \\
Normal & 0 & 2 & 0 & 13 & 29 \\
Total & 1 & 2 & 13 & 2 & \\
\hline
\end{tabular}

There was statistical association between the echogenesity of the liver and the ascetic fluid volume among the respondents $(P$ value $=0.024)$ (Table 8$)$.

Table 9. Cross tabulation of the para-aortic lymph nodes volume and ascetic fluid volume among the respondents with ascites attending Ultrasound Department, Elribat Teaching Hospital, Sudan; 2016 ( $n=29)$.

\begin{tabular}{|c|c|c|c|c|c|c|}
\hline \multirow{2}{*}{$\begin{array}{l}\text { Para-aortic lymph nodes } \\
\text { volume }\end{array}$} & \multicolumn{4}{|c|}{ Ascetic fluid volume } & \multirow{2}{*}{ Total } & \multirow{2}{*}{ Pvalue } \\
\hline & Missed & Minor ascites & Moderate ascites & Gross ascitis & & \\
\hline Missed & 1 & 0 & 0 & 1 & 2 & \multirow{5}{*}{0.027} \\
\hline Increased & 0 & 1 & 1 & 1 & 3 & \\
\hline Normal & 0 & 0 & 2 & 3 & 5 & \\
\hline Not seen & 0 & 1 & 10 & 8 & 19 & \\
\hline Total & 1 & 2 & 13 & 13 & 29 & \\
\hline
\end{tabular}

There was statistical association between the para-aortic lymph nodes volume and ascetic fluid volume among the 


\section{Discussion}

The percentage of increased liver echogenesity; volume; width; and diameter; was found to be high among respondents. The width and diameter of the spleen was increased among most of the respondents. This is an indication of extensive liver injury; which is associated with ascites. These findings were consistent with international publications [16, 22]. There was strong statistical association between the echogenesity of the liver and that of the spleen. Also there was statistical association between the echogenesity, diameter, width, and volume of para-aortic lymph nodes; and the ascetic fluid volume among the respondents. International findings indicate that ascites is a multi-organ problem, where manifestations can be detected in all above mentioned organs [14, 17]. The echogenesity of both right and left kidneys was increased among majority of the respondents; while their volume, width, and diameter were normal among majority of them. There was strong statistical association between the echogenesity of the right kidney and that of the left kidney. This was an indication of equal manifestations of the disease on the renal system. In these cases the possible cause may be renal [4, 6, 7]. Regarding the ascetic fluid volume there was equal distribution of moderate and gross ascites amongrespondents. There was statistical association between the para-aortic lymph nodes volume and ascetic fluid volume among the respondents. Possibly this may be explained by infectious disease involving the para-aortic lymph nodes in these cases $[16,22]$. The echogenesity of the spleen together with the echogenesity of the pancreas were statistically associated with the echogenesity of paraaortic lymph nodes among the respondents. Involvement of the spleen and para-aortic lymph nodes indicates an infectious origin of the disease that lead to development of ascites $[14,22]$.

\section{Conclusion and Recommendations}

Ultrasound is a useful noninvasive easily accessible tool for diagnosis the ascites by measuring its volume and evaluating its texture as routine imaging investigations. It can suggest the possible cause, differentiates between the transudates and exudates ascites with a reasonable sensitivity. Involvement of the liver and spleen was quite obvious among patients having ascites. Conduction of a research to correlate the sonographic findings with diagnosis of the disease is highly recommended. To increase utilization of abdominal ultrasound, we recommended training of medical staff through short courses and seminars.

\section{References}

[1] Runyon BA. Ascites and spontaneous bacterial peritonitis. In: Feldman M, Friedman LS, Brandt LJ, eds. Sleisenger \& Fordtran's Gastrointestinal and Liver Disease. 9th ed. Philadelphia, Pa: Saunders Elsevier; 2010: chap 91).
[2] Cesario K. B., Choure, A., Carey, W. D. Cirrhotic Ascites. Cleveland Clinic - Center for Continuing Education. Disease Management Project Hepatology. Published: April, 2013.

[3] British Society of Gastroenterology. Guidelines on the Management of Ascites in Cirrhosis; (2006).

[4] Runyon BA; AASLD Practice Guidelines Committee. Management of adult patients with ascites due to cirrhosis: Update 2012.

[5] American Association for the Study of Liver Diseases. 2013.

[6] Mehta G, Rothstein KD. Health maintenance issues in cirrhosis. Med Clin North Am. 2009; 93: 901-915.

[7] Garcia-Tsao G. Cirrhosis and its sequelae. In: Goldman L, Ausiello D, eds. Cecil Medicine. 24th ed. Philadelphia, Pa: Saunders Elsevier; 2011: chap 156.

[8] Su M. H. et al. Update on the differential diagnosis of gynecologic organ-related diseases in women presenting with ascites. Taiwanese Journal of Obstetrics \& Gynecology 58 (2019) 587-591.

[9] Ueli B. Ascites in cattle: ultrasonographic findings and diagnosis. The Veterinary clinics of North America. Food animal practice, 2016; 32 (1): 55-83. DOI: https://doi.org/10.1016/j.cvfa.2015.09.004.

[10] Franz M. and $\mathrm{HO} \mathrm{rl} \mathrm{W}$. H. The patient with end-stage renal failure and ascites. Nephrol Dial Transplant (1997) 12: 1070 1078 .

[11] Natnaael Kidanu Yibalih, Dawit Wolday, Samuel Kinde, Gebru Mulugeta Weldearegay. External Quality Assessment on CD4+ T-Cell Count Using in-House Proficiency Testing Panels for CD4 Count Laboratories in Addis Ababa, Ethiopia. Ethiop J Health Sci. 2019; 29 (3): 383. doi: http://dx.doi.org/10.4314/ ejhs.v29i3.11.

[12] Alnumeiri MS, Ayad CE, Ahmed BH, Abdalla EA Evaluation of Ascites and its Etiology Using Ultrasonography. J Res Development, 2015; 3: 1 doi: 10.4172/2311-3278.1000119.

[13] Rose J. S. Ultrasound in abdominal trauma. Emerg Med Clin N Am, 2004; 22; 581-599.

[14] Espírito Santo M. C. C. D.; Azeredo, 1. M.; Teles, H. M. S.; Gryschek, R. C. B.; Ferreira, C. S. \& Neto V. A., Abdominal Ultrasound in the Evaluation of Fibrosis and Portal Hypertension in an Area of Schistosomiasis Low Endemicity. Rev. Inst. Med. Trop. S. Paulo 50 (2): 117-119, March-April, 2008.

[15] Kuiper JJ, van Buuren HR, de Man RA; Ascites in cirrhosis: a review of management and complications. Neth J Med. 2007 Sep; 65 (8): 283-8.

[16] Kashani A, Landaverde C, Medici V, et al; Fluid retention in cirrhosis: pathophysiology and management. QJM. 2008 Feb; 101 (2): 71-85. Epub 2008 Jan 9.

[17] Jain R., Sawhney S., Bhargava D. K., and Berry M. Diagnosis of Abdominal Tuberculosis: Sonographic Findings in Patients with Early Disease. AJR 1995; 165: 1391-1395.

[18] Agarwal D., Narayan S., Chakravarty J. \& Sundar S. Ultrasonography for diagnosis of abdominal tuberculosis in hivinfectedpeople. Indian J Med Res 132, July 2010, pp 7780. 
[19] Sinkala E., et al. Clinical and ultrasonographic features of abdominal tuberculosis in HIV positive adults in Zambia. BMC Infectious Diseases 2009, 9: 44 doi: 10.1186/14712334-9-44.

[20] Atzori S., Vidili G., Delitala G. Usefulness of ultrasound in the diagnosis of peritoneal tuberculosis. J Infect DevCtries 2012; 6 (12): 886-890.
[21] Sood R. Ascites: Diagnosis and Management. Journal of Indian Academy of Clinical Medicine _ Vol. 5_ No. 1.

[22] Karin B. Cesario, AnujaChoure, William D. Carey. Cirrhotic Ascites. Cleveland Clinic - Center for Continuing Education. Disease Management Project Hepatology. Published: April, 2013. 